\title{
EL CONFLICTO SOCIAL EN LA HISTORIA DE VIDA DEL LÍDER DE TRABAJADORES AGRÍCOLAS EN SINALOA: \\ EL CASO DEL FRENTE UNIFICACIÓN LUCHA TRIQUI
}

Celso Ortiz Marín

\section{Resumen}

Los enclaves de agricultura intensiva conforman mercados de trabajo muy dinámicos, generando movimientos y asentamientos de la población, y Sinaloa no es la excepción. Sin embargo, los migrantes indígenas se ven excluidos como migrantes y como indígenas en términos económicos, sociales, políticos y laborales. Para hacerle frente a toda esta problemática, a partir de los años noventa en Sinaloa los jornaleros agrícolas migrantes indígenas adoptan una nueva modalidad de organización. La característica principal de estas organizaciones es el carácter étnico que revisten y la orientación de su lucha hacia aspectos que competen a la defensa de los derechos humanos, así como en torno a demandas de carácter civil o laboral. No obstante, en estas organizaciones se destaca la presencia protagónica de actores sociales que son reconocidos entre los trabajadores agrícolas. La presente investigación analiza el conflicto social en la historia de vida del líder.

Palabras clave: horticultura, organización, trabajadores agrícolas, conflicto social y actor social.

\section{Abstract}

The locations of intensive agriculture configure highly dynamic labor markets, generating population movements and settlements, Sinaloa is not an 
exception. They are, however, economical, social, political and laboral excluded both as migrants and as indigenous people. In order to face these problems, in Sinaloa, since the 1990s, indigenous migrant agricultural workers have adopted a new organization modality. The main feature of these organizations is their ethnic character and the orientation of their struggle towards aspects pertinent to human-rights defense as well as demands of civil or labor character. Within these organizations, the protagonist presence of social actors acknowledged by the agricultural workers outstands. This research analyzes the social conflict throughout his life.

Key Words: horticulture, organization, agricultural workers, social conflict and social actor

\section{INTRODUCCIÓN}

Existen estudios sobre la constitución de nuevos espacios y actores sociales asociados a la migración indígena. Un primer enfoque se ha centrado en el entendimiento de las causales de la migración indígena y la incorporación de estos grupos en sus lugares de destino (Iwanska, 1973; Arizpe, 1980; Méndez y Mercado, 1985; Lewis, 1986). Otro enfoque estudia las formas de vida de los migrantes en la ciudad, sus mecanismos y sus estrategias de adaptación (Kemper, 1976; Bustamante, 1986). El tercer enfoque aborda el surgimiento, mantenimiento y continuidad de las asociaciones de migrantes (Odena, 1983; Velasco, 2002; Fox y Rivera, 2004 y Ortiz, 2007). Sin embargo, el tema de la constitución de actores individuales como los líderes indígenas en el marco de la migración interna en México $^{1}$ ha sido escasamente tratado y mucho menos en el contexto de los mercados de trabajo rural de los estados del noreste del país.

Cabe señalar que existen trabajos cercanos a este tema con otros referentes empíricos. Puede mencionarse la investigación de Taylor (1979) sobre la defensa de los trabajadores agrícolas que encabeza Cesar Chávez contra los grandes monopolios y los poderosos terratenientes de Estados Unidos; el trabajo de Besserer (1999), que analiza la historia de un transmigrante (Moisés Cruz) dentro de la internacionalización del capital y la fuerza de trabajo, así como la formación trasnacional de la experiencia y la identidad; por su parte, Paris (2006) estudia las rutas migratorias que recorre Martha (mujer indigena triqui)
con sus familiares a los campos agrícolas del noroeste de México y California y la transformación de la convivencia comunitaria y las relaciones de género entre los indígenas migrantes. Existe también el trabajo de Velasco (2002) quien analiza a los intelectuales mixtecos y cómo éstos aportan en la creación de una comunidad énica trasnacional; y la investigación de Leal (2006) sobre el papel fundamental de
En Sinaloa a partir de los años noventa existen organizaciones donde se destaca la presencia protagónica de actores sociales que son reconocidos entre los trabajadores agrícolas. Se trata de un actor indígena, y se refiriere a los líderes indígenas que son resultado de la integración conflictiva de los grupos indígenas a los mercados de trabajo agrícola. Es evidente que estos actores sociales están generando una reflexión propia sobre sí mismos, sobre su organización, el trabajo agrícola y los desafíos que enfrentan y lo hacen a partir de un cruce entre sus propias prácticas culturales y su identidad de indígenas. Estos actores indígenas tienen una reflexión propia, un pensamiento individual que el mundo académico necesita conocer y re-conocer, pero también para la construcción de una sociedad más justa. La presente investigación retoma la metodología del actor y analiza el conflicto social en la historia de vida del líder. En el primer apartado se describe la agricultura sinaloense y el trabajo agrícola, posteriormente, la historia de vida y el conflicto social en el líder del Frente Unificación Lucha Triqui.

\section{A) LA AGRICULTURA SINALOENSE Y EL TRABAJO AGRÍCOLA}

Sinaloa es un estado que tiene condiciones naturales propicias para la agricultura. Lo atraviesan once ríos ${ }^{2}$ y cuenta con clima, altitud y humedad adecuados, así como con extensos Valles que hacen de la entidad un lugar privilegiado para el desarrollo de esta actividad, reúne condiciones privilegiadas con respecto a otros estados de la república, cuenta, con la mayor superficie agrícola bajo riego en el país, gracias a la existencia de una infraestructura hidráulica sin paralelo en el plano nacional.

De 1 C469,443 hectáreas abiertas al cultivo ( $73.6 \%$ ejidales y $26.4 \%$ privadas) el $54.7 \%$ son de riego y $45.3 \%$ de temporal. Las cuales están bajo el control de 148,480 productores ( $86 \%$ ejidales y $14 \%$ privados) (PEE/SHPyT, 2001). Los espacios ejidales y privados del sector agrícola sinaloense han evolucionado con dificultades productivas crecientes, debido a fenómenos naturales, controversias económicas y convulsiones políticas.

Sinaloa actualmente es un mosaico de cultivos. En sus campos encontramos, caña de azúcar, soya, maíz, garbanzo, sorgo, trigo, cártamo, cacahuate, ajonjolí, algodón, fríjol, arroz, alfalfa, cebolla, flor de cempasúchitl y frutales. Así, como

${ }^{2}$ Tienen una capacidad de almacenamiento de más de 15 mil millones de metros cúbicos. 
una gran variedad de hortalizas cultivadas con la más avanzada tecnología -como la hidroponía y el riego por goteo- importada en su mayoría de Holanda e Israel, adaptada y transformada por manos mexicanas. Hay pimientos rojos, verdes, amarillos, morados y cafés, tomates, pepinos, berenjenas de diferentes variedades y tamaños, sandía, calabaza, chile, papa, melón. A lo largo de los años se ha producido una evolución en la producción de hortalizas como consecuencia de la variación que han experimentado las demandas en los mercados.

La producción de hortalizas en Sinaloa se realiza en los distritos de riego de los valles agrícolas del estado. En la temporada 2009-2010, se cultivó una superficie de 55, 105 mil hectáreas? y la exportación de hortalizas ascendió a 972 mil toneladas, lo que generó una derrama económica de 1, 186 millones de dólares. Los principales cultivos de hortalizas han sido el tomate, pepino, chile bell, berenjena y calabacita. Durante la temporada otoño-invierno 2009-2010 se destinaron 12, 760 hectáreas para el cultivo de tomate; 2996 para el pepino; 15805 chile Bell; la berenjena con 1055 y la calabacita con 4 465, todos ellos bajo el sistema de riego (CAADES, 2010).

La elevada productividad agrícola que se desarrolla en la superficie de riego ha permitido que un número importante de empresarios acumulen capital y realicen inversiones, tecnificando y modernizando. Gámez (2006) señala que hay trece productores en el estado que concentran más de $50 \%$ de la fuerza de trabajo que contrata y concentran los campos hortícolas más importantes (cuadro 1)

\section{Cuadro 1}

\section{Principales Horticultores de Sinaloa}

\begin{tabular}{|c|c|}
\hline Compañía & Productor \\
\hline Sigma Produce & Trifonas Strabrospulus \\
\hline Tricar & Daniel Cárdenas Izábal \\
\hline Rene Produces Distribuidor INC & René Carrillo Carranza \\
\hline Farmer Best & Roberto Tarriba Rojo \\
\hline Bravo Distributing Inc & José María Gallardo \\
\hline Omega Produces Inc & George Gotsis \\
\hline Melgose Produce Distributors & José U. López \\
\hline
\end{tabular}

\begin{tabular}{|c|c|}
\hline GAC Produce INC & Familia Canelos \\
\hline Lisa INC & Familia Litchter \\
\hline Tare Distributing Company & Hermanos Tamayo \\
\hline Su Casa Produce Inc & Tres productores no especificados \\
\hline Rolit & Jorge y Enrique Rodarte \\
\hline San Rafael & Adolfo y Marco Antonio Clouthier \\
\hline
\end{tabular}

Fuente: Gámez Gastélum, Rosalinda (2006).

Lara y C. De Grammont (2011) mencionan que las empresas de punta, aquellas que se mantienen en el mercado abierto y se transforman en empresas globales, transnacionalizadas e integradas a complejos consorcios, cambiaron radicalmente su tecnología, abandonando el paradigma de la Revolución Verde. Los principios básicos de estas nuevas tecnologías son el ahorro de energía no renovable (agua), y la disminución de agroquímicos, asimismo, hay el uso de nuevas semillas que permiten obtener una mayor homogeneidad en la maduración del fruto y mayor vida de anaquel, el riego presurizado, la fertirrigación, la balanza cero, la plasticultura y la agricultura protegida (invernaderos o malla sombra) (Lara y C. De Grammont, 2011:46).

Sin embargo, para el desarrollo de esta agricultura empresarial y por la superficie dedicada a la siembra de hortalizas, año con año Sinaloa atrae a uno de los contingentes más numerosos de trabajadores agrícolas del país. El número estimado de jornaleros en Sinaloa varía dependiendo de la fuente de información que lo proporcione. El Programa de Atención a Jornaleros Agrícolas de $2007^{3}$ menciona que cada temporada llegan cerca de 200, 000 jornaleros a trabajar en los campos agrícolas. Por su parte, Guerra (1998:27) calcula entre 200000 y 300000 jornaleros agrícolas arriban al estado.

En Sinaloa, la fuerza de trabajo que se emplea en las labores ligadas a la producción hortícola en los campos es fundamentalmente migrante: $26.2 \%$ de estos trabajadores son migrantes originarios del mismo estado que se trasladan de los altos o de comunidades alejadas a los valles; y $73.8 \%$ pertenece a la corriente de trabajadores que se trasladan de los estados de Guerrero (32.1\%), Oaxaca (26.2\%), Guanajuato (3.3\%), Durango (2.6\%), Veracruz (2.5\%), Zacatecas (2.2\%), Michoacán (2.1\%), Chihuahua (0.9\%), Puebla (0.8\%)

${ }^{3}$ Datos del Programa de Atención a Jornaleros Agrícolas, entrevista personal con el Lic. Arturo López Ruiz 
y otros estados (1.1\%) (Secretaría de Salud, 2001). Los migrantes provienen, predominantemente, de los estados de Guerrero y Oaxaca. Los principales municipios expulsores son Metlatónoc, Xalpathahuac y Tlapa, en Guerrero; Juxtlahuaca, San Martín Peras, Ejutla de Crespo y Coatecas Alto, en el caso de Oaxaca. Los indígenas de mayor presencia son los mixtecos, seguidos por los zapotecos, triquis, tlapanecos y nahuas (SEDESOL, 1999).

Si bien, la mayor parte de los jornaleros agrícolas provenientes de Oaxaca y Guerrero regresa a su lugar de origen, algunos optan por asentarse cerca de los campos agrícolas sinaloenses. El asentamiento de población de origen oaxaqueño y guerrerense se ha incrementado en forma considerable a partir de la década de los ochenta. Sin duda, este asentamiento de población se debe al incremento de las actividades hortícolas, como lo prueba el hecho de que el $83.4 \%$ de la población de origen oaxaqueño y el 86.9 de origen guerrerense se establecen en el Valle de Culiacán, mismo que comprende los municipios de Culiacán y Navolato, donde se localiza la mayor parte de la actividad hortícola (Granados, 2000). Para el año 2000 se estimaba que había 37638 inmigrantes de Oaxaca y 19438 inmigrantes de Guerrero en el estado de Sinaloa (INEGI, 2000).

No obstante, los migrantes indígenas se ven excluidos como migrantes y como indígenas en términos económicos, sociales y laborales. En un estudio realizado por el Centro de Derechos Humanos de la Montaña de Tlachinollan (2011) señala que en los campos agrícolas de Sinaloa: a) no hay contratos laborales formales; b) las viviendas y sus servicios se encuentran en malas condiciones, incluso algunas no tienen energía eléctrica, agua potable, regaderas, sanitarios y lavaderos; c) los empresarios no les garantizan el transporte de regreso a su lugar de origen; d) suspensión de labores o pago incompleto de su salario por ausentarse del campo, incluso por cuestiones de salud; e) el servicio médico de las clínicas de los campos agrícolas es deficiente e irregular, ya que el horario de atención es incompatible con la jornada de trabajo; f) los productos de la canasta básica se venden a altos precios en las tiendas de los campos agrícolas y; g) Sinaloa es el estado en donde se reporta el mayor número de fallecimiento de jornaleros y jornaleras agrícolas por cuestiones de salud, falta de atención médica oportuna, negligencia médica, accidentes por riesgo de trabajo u otras circunstancias.

Para hacerle frente a toda esta problemática, a partir de los años noventa en Sinaloa los jornaleros agrícolas migrantes indígenas adoptan una nueva modalidad de organización. La característica principal de estas organizaciones es el carácter étnico que revisten y la orientación de su lucha hacia aspectos que competen a la defensa de los derechos humanos, así como en torno a demandas de carácter civil o laboral. Dentro de la organización se destaca la presencia protagónica de actores sociales que son reconocidos entre los trabajadores agrícolas, tal es el caso del líder del Frente Unificación Lucha Triqui (FULT). En el siguiente apartado se conocerá la historia de vida y migración del líder del FULT.

\section{B) HISTORIA DE VIDA Y MIGRACIÓN DEL LÍDER DEL FULT}

El líder del FULT nace un 27 de junio de 19774 en San Juan Copala, distrito de Juxtlahuaca, Oaxaca. Hijo de Maria Florencia de Tilapa, San Juan Copala y Regino López García, originario de un pueblo cerca de Yosoyuxi y Tierra Blanca. Al pueblo de su madre y padre sólo los divide el cerro Cruz Chiquita. Único hijo de este matrimonio. Sus padres ya habían estado casados, donde su madre tuvo un hijo y su padre dos hijos (hombre y mujer).

El nombre de Juan López García lo hereda de su abuelo, hombre que se destacó por su participación en las autoridades de usos y costumbres que rigen a los triquis. Su abuelo era encargado de convocar a juntas y organizar el tequio entre las comunidades, que estaban conformadas de dos o tres familias y se encontraban a grandes distancias una de la otra:

"A mí me puso mi apá Juan López García porque era su papá [...] Si por eso mi apá quiso que heredara el nombre de él Juan López García por eso yo no tengo el apellido de mi mamá. A ella le agregamos el García porque ella tampoco tiene acta de nacimiento; pero pues yo tengo el nombre de mi abuelo [...] Ya ves que el apellido nunca coincide cada quien se pone el apellido que quiere [...] Ajá que cuando es tequio en organizar alguna reunión o cuando le dan unas autoridades, o los mismos pobladores cuando hacía reuniones él convocaba. Había gente triqui en las regiones más lejanas de dos o tres casitas porque ellos se agrupaban., que Río Venado, que Río Humo que en Yerba Santa, y venían siempre a buscarlo" (entrevista con Juan López García, FULT, Villa Benito Juárez, Navolato)

A los pocos meses de haber nacido Juan López, sus padres deciden ir a vivir a la comunidad Río Tejón, tierras ancestrales que les pertenecían a los triquis, pero que años antes habían sido invadidas por mestizos de Putla de

Esta fecha le pone a su acta de nacimiento, pero en realidad no sabe el día y el año que nació, sino hicieron 
Guerrero, Oaxaca, y a mediados de los setenta deciden recuperarlas y fundar la comunidad de Río Tejon. Sus padres y otras familias se van a vivir al pueblo de reciente creación. Su familia estaba integrada por su papá, su esposa, la mamá de Juan y Luís el hijo de su mamá. Sus primeros años transcurren en Río Tejon, donde sus padres se dedican a la siembra de maíz y fríjol en las laderas de los cerros, la producción se destina sólo al autoconsumo, asimismo, se dedican a la caza de conejos y venados para complementar la alimentación.

Sus primeros tres años de vida transcurrieron sin sobresaltos en su comunidad Río Tejon, pero se vio violentada a su escasa edad por la invasión que nuevamente hicieron los mestizos de Putla de Guerrero. Durante dos o tres semanas hubo intercambio de balazos entre ambos bandos, el resultado fue la muerte de cuatro triquis de una familia y a su padre le tocó hacer las tumbas para los muertos:

“...nomás que ese poblado como te digo que fue invadido fueron a arreglarlo l estilo del sur entonces pues los corrieron a balazos a la gente que vivía ahi, que eran de Putla no son triquis pues. Ellos también la respondieron hubo que eran de punas no so tres semanas ahi pleito como unas dos [. está lo toco ir a [...] Hubor cuatro mu día hizo cuatro exavaciones, hicieron cuatro tumbas y dijo mi papá " $y a$ mo puedo estar aquíhaciendo las tumbas de estos amigos y vámonos"fue "ya no pulimos de pueblo" (entrevista con Juan López Garcí, FULT, Villa Benito Juárez, Navolato)

De esta manera, debido a la violencia que se vive en la región triqui por la disputa de tierras con sus vecinos mestizos de Putla de Guerrero, la familia de Juan decide salir de la comunidad Río Tejon. Asimismo, no deciden quedarse en la región triqui, porque a pesar que su padre tenía un terreno estaba en disputa con un hermano suyo. De ahí, que decidieran buscar otras alternativas de vida y emprenden la migración por primera vez hacia Cuautla, Morelos, al corte del tomate de cáscara y jitomate.

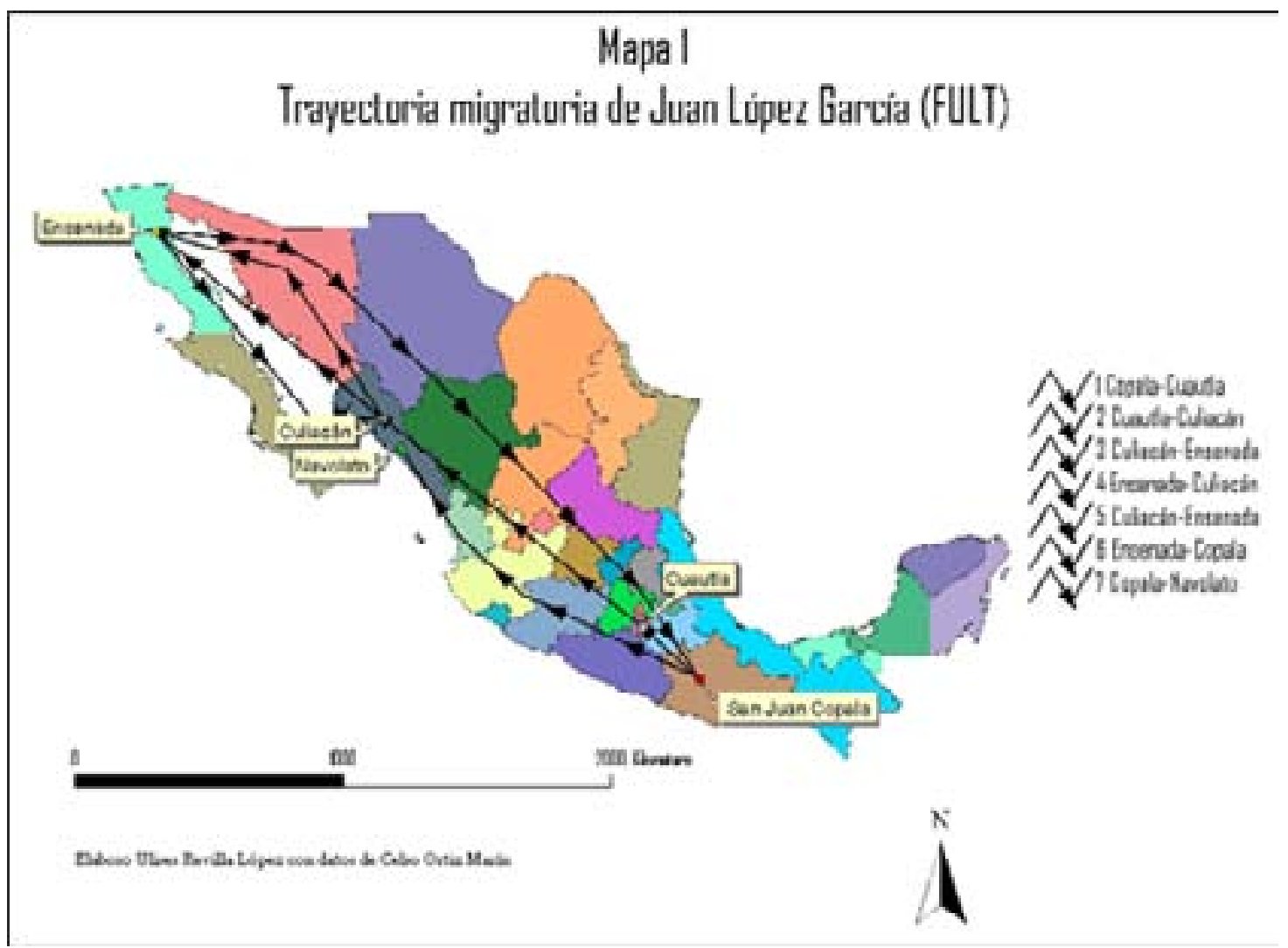

El estado de Morelos para la década de los setenta destaca por su gran producción de jitomate y por requerir mano de obra para su cosecha. Guzmán (1991) menciona que desde mediados de la década de los cincuenta ${ }^{5}$ se

${ }^{5}$ Antes de mediados de la década de los cincuenta en Los Altos de Morelos el jitomate y tomate de cáscara se cultivaban de manera tradicional en huertas de traspatio que eran destinadas para el autoconsumo (Guzmán, 1991: 62). Sin embargo, en 1955, un inmigrante italiano que vivía en Cuautla alquiló algunas tierras en el uso de semillas importadas seleccionadas, fertilizantes, insecticidas y una estructura hecha de estacas y alambre -semejante a la utilizada en los viñedos-, para mantener la planta por encima del suelo y de este modo evitar que el fruto se pudriese al contacto con la tierra húmeda. Algunos campesinos comenzaron a

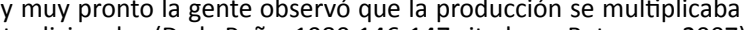


introducen métodos modernos para el cultivo del jitomate, destacando las semillas mejoradas, fertilizantes químicos y uso de tractores. La producción de jitomate en Morelos fue aumentando considerablemente a lo largo de los años sesenta. Esta década fue en realidad de experimentación, conocimiento de cultivo y adaptación a sus propias condiciones de producción; asimismo fue una década de apertura al exterior, de nuevas relaciones con los mercados, centros urbanos, agentes económicos y políticos. Al inicio de los setenta, productores chicos y grandes, contaban con una gran experiencia, a lo largo de la década lograron producciones más o menos altas. En 1970 el cultivo del jitomate era el más importante del estado de Morelos y en 1971 era el segundo estado del país productor de esta hortaliza (Guzmán, 1991: 65-69).

Es de suponer que la mano de obra no fue suficiente para la cosecha de jitomate, de ahí que empezaron a llegar trabajadores agrícolas de otros estados, y una de ellas fue la de los triquis. Esto no quiere decir que las primeras olas migratorias de triquis a Morelos fueron a partir de la década de los setenta, sino más bien en esa época es cuando migra la familia de Juan López y encuentran a familias triquis trabajando en Morelos desde años atrás:

“...nos fuimos a Cuautla, Morelos estuvimos trabajando ahí y ahí fue cuando comenzamos a salir. Ya ahí fue cuando encontramos a una familia triqui que ya vivia en Cuautla, Morelos, que son las familias que aquí están ahorita. Es la señora que te digo que se fue a la religion, a pues estaba ella, estaba su esposo, estaban todos los chiquillos. Ahi nos juntamos y estábamos en Cuautla... Ya con Juan López García, FULT, Villa Benito Juárez, Navolato)

El traslado de la zona trique hacia Morelos era costeada por los propios trabajadores agrícolas. La llegada a Morelos represento una experiencia dolorosa, implicó salir de su localidad de origen pensando siempre en el regreso. Pero también se pensó en mejorar sus condiciones de vida a través del acceso al trabajo agrícola. No obstante, pronto se desencantaron por las condiciones de trabajo y vida, que eran mucho más precarias e insalubres que las que experimentaban en su lugar de origen.

Llegan a trabajar con rancheros en sus campos de jitomate o tomate de cáscara. Todas los días a partir de las cinco de la mañana los hombres y mujeres mayores tenían que estar listos para ser trasladados a los campos al corte de jitomate o tomate de cáscara. Los niños no participaban en las labores agrícolas, se quedaban al cuidado de algún hermano. La llegada a los campos era a las 7 de la mañana, donde laboraban más de 10 horas diarias, durante los 7 días de la semana. Los salarios eran bajos, en ocasiones trabajaban horas extras sin que recibieran algún pago más, recibían maltrato por parte de los encargados de las cuadrillas e incluso discriminación.

os trabajadores agrícolas vivían en casas de cartón en los alrededores de la ciudad de Cuautla, Morelos. Casas que eran construidas por los propios rancheros para hospedar a sus trabajadores agrícolas. Las condiciones de vida eran precarias e insalubres, los baños eran fosas sépticas o incluso se veían en la obligación de defecar en los cultivos que se encontraban en los alrededores de las casas. No había lavaderos, ni agua para lavar la ropa o para bañarse:

“Cuando nos fuimos a Cuautla, Morelos yo tenía cinco años apenas... mi apá pago todos los pasajes, íbamos su esposa, mi apá, mi mamá y yo, Luís el hijo de mi mamá se quedó en Oaxaca estudiando y cuando tenía vacaciones iba a Cuautla, Morelos a trabajar y se iba otra vez para allá [...] Mi mamá me cuenta que vivíamos con unos rancheros que los llevaban a trabajar y decía mi papá que estaba muy peligroso porque iban muy lejos a trabajar al tomatillo. Yo me quedaba con otros niños a jugar todo el día [...] ella dice que les pagaban muy poco y trabajaban a veces hasta 10 horas al día, les gritaban y los maltrataban poco y trabajaban a veces hasta 10 horas al día, les gritaban y los maltrataban mucho [...] habia mucha escasez de agua, la gente que tenía pozo grande de agua nos vendian agua para lavar o bañarse, baños no había y sí habia eran pueblo pero al menos ahí ya no había muertos decía mi apá" (entrevista con Juan López García, FULT, Villa Benito Juárez, Navolato)

A pesar de las condiciones de trabajo y vida precarias que experimento la familia de Juan López en Cuautla, Morelos, permanecen durante casi dos años en el corte de jitomate y tomate de cáscara. Cabría preguntarse ¿por qué no regresaron a su pueblo de origen? La razón se debió a la violencia que se estaba viviendo en esos años por la invasión de sus tierras, falta de oportunidades de trabajo en la región y al conflicto de tierras que mantenía su padre con algunos de sus hermanos.

Para el año de 1982, cuando se encuentran en Cuautla, Morelos trabajando en el corte de jitomate, la familia de Juan López recibe la invitación de algunos paisanos para ir a trabajar a los campos de Sinaloa. Deciden probar suerte porque se les menciona que el salario es más alto que en Morelos, se les promete condiciones de vida mejores y además quienes decidieran irse ya iban contratados para el trabajo agrícola.

Es así como Juan López a los cinco años de edad emprende el viaje con su familia al estado de Sinaloa. Para ese entonces se va con su papá, la otra esposa de su padre y su madre. Junto a ellos también se van otras familias de triquis a Sinaloa, entre ellos varios paisanos de su lugar de origen que también trabajaban en Morelos. El viaje es pagado por el contratista y los transporta en 
tren. El traslado de los trabajadores agrícolas recorrió la siguiente ruta en tren: de Morelos los trasladan a la Ciudad de México y de la Ciudad. de México a Navolato, Sinaloa. El viaje duró aproximadamente 8 días, donde ellos tuvieron que pagar sus comidas, y al no contar con suficientes recursos económicos comían una sola vez al día:

"Cuando nos fuimos a Sinaloa, iba mi apá, mi mamá, la otra señora (la esposa de su papá) otras familias triquis con sus esposos y todos sus hijos. Una tarde que había llegado mi apá del trabajo, llego un paisano de él y le dijo que había "contrata" para ir al corte de jitomate a Sinaloa, que se pagaba más que aquí (Cuautla, Morelos) y daban buenas casas y pagaban el tren para irse [...] después de varios días mi apá llego y nos dijo "alistense que mañana nos vamos a Sinaloa" $y$ así fue como nos venimos para Sinaloa. El viaje fue largo, vamos a Sinaloa" $\mathrm{y}$ asi fue como nos venimos para Sinaloa. El viaje fue largo, a Navolato, comíamos poquito porque no traía mucho dinero mi apá, pero fue a Navolato, comiamos poquito porque no traia mucho dínero mi apá, pero fue Benito Juárez, Navolato)

Llegando a Navolato, Sinaloa, en la terminal del tren ya los esperaba el contratista del patrón para trasladarlos a los campos agrícolas, donde iban a permanecer hasta cuatro meses en el corte de jitomate. Al primer campo que los llevan a trabajar fue al campo "Oaxaca"6, propiedad de la familia Canelos. Los metieron a vivir por familias a cuarterías de cartón que se encontraban a las orillas de los campos agrícolas, que durante las lluvias se filtraba el agua por las orillas, el piso era de tierra, no contaban con luz eléctrica, ni con agua potable para lavar su ropa o bañarse, sino muchas veces tenían que bañarse en los canales de riego e incluso bebían esa agua.

La jornada laboral empezaba a partir de las siete de la mañana, pero debían levantarse a las cinco de la mañana para preparar sus alimentos que comerían durante el día. Al trabajo agrícola sólo iban los adultos. La jornada laboral era de 10 a 12 horas al día durante los siete días de la semana. El trabajo lo realizaban en cuadrillas, pero el cuadrillero no era gente de su pueblo, sino personas mestizas de la sierra de Sinaloa, lo que dificultaba el entendimiento con ellos por no hablar el español, eso traía como consecuencia la discriminación. El trabajo era arduo porque se tienen que meter entre los surcos para el corte de jitomate o pepino que en ocasiones estaban inundados de agua los surcos que incluso les llegaba hasta las rodillas.

Se le conocía como campo Oaxaca porque todos los trabajadores agrícolas que laboraban ahí provenían Se le conocía como car
“Cuando llegamos a Sinaloa yo ya tenía como siete años, yo no trabajaba; sólo mi apá, su esposa y mi mamá. Ellos se levantaban muy temprano y llegaban hasta casi cuando ya no había sol. Había galerones de lámina de cartón, pero os pisos eran de tierra. Agua... pues no, no había, tomábamos del canal y ahí nos bañábamos. Ese campo tenía galeras de lámina de cartón, y cuando llovía se metia toda el agua. Había muchos ratones, comían tomates, tortilla, todo lo que encontraban [...] Pues antes no habia la gente de nosotros, no andaba la gente de nosotros de cuadrilleros, ni de... no ocupaban la gente de nosotros, ocupaban la pura gente de ellos, ellos eran los que mandaban a la gente, y dirigian a la cuadrilla. Se metian en el agua, a cortar tomate o a cortar pepino entraban en la zanja y el agua les llegaba hasta la rodilla, habia mucho agua, así era el trabajo" (entrevista con Juan López García, FULT, Villa Benito Juárez,
Navolato)

Trabajan durante toda la temporada en el campo Oaxaca, que dura casi cinco meses, donde los padres de Juan López no alcanzan a juntar el suficiente dinero para regresar a Oaxaca. Además, su padre tuvo que enfrentar una demanda que le hizo su otra esposa por usos y costumbres en San Juan Copala, Oaxaca, donde le exigía un pago para separarse de ella. Al final el padre de Juan López y su madre accedieron pagar la multa entre los dos para que se separara de su otra esposa. El dinero lo fueron ahorrando del pago que adquieren por el trabajo del corte de jitomate y pepino en el campo Oaxaca. Así, antes de terminar la temporada agrícola en Sinaloa el padre de Juan López viajó a San Juan Copala a pagar la multa que se le exigía para su separación.

Al regreso del padre de Juan López a Sinaloa casi terminaba la temporada agrícola, donde se habían quedado sin dinero y empezaba a escasear el trabajo. Tal motivo hace que decidan regresar a Oaxaca, porque consideran que en Sinaloa también pagan poco, las condiciones de trabajo y vida eran malas, y no les gustó las temperaturas porque son muy altas que en ocasiones llegan hasta los $36 \circ \mathrm{C}$ y habían demasiados moscos en los canales de riego que les ocasionaban picaduras. Cuando la familia de Juan López había decidido regresar a San Juan Copala, el dueño del campo Oaxaca (Los Canelos) ofreció trabajo a todos sus trabajadores agrícolas para irse al corte de jitomate en los campos agrícolas que tenía en Ensenada, Baja California.

En el año de 1983, Juan López, quien tenía la edad de seis años, emprende el viaje con su familia (sólo queda su padre, su madre y él) hacia los campos agrícolas de la familia Canelos que tienen en Ensenada, Baja California. El trasporte de Sinaloa a Ensenada, Baja California es pagado por la familia Canelos. El viaje se realiza en tren de Navolato, Sinaloa a Mexicali, Baja California y el último tramo de Mexicali a Ensenada se hace en camión. El recorrido de Sinaloa a Ensenada, Baja California dura aproximadamente ocho días. 
Cuando llega la familia de Juan López a Ensenada, Baja California, los llevan al campo agrícola Llama, propiedad de la familia Canelos, donde los alojan en las cuarterías que existían en el campo agrícola. Las condiciones de trabajo y vivienda son las mismas que habían encontrado en Sinaloa: casas de cartón, piso de tierra, falta de agua potable, jornadas laborales de $10 \mathrm{hrs}$., jornadas extras de trabajo, bajos salarios, maltrato y discriminación, el traslado de los campamentos al campo agrícola se hacía de forma insegura:

“Nos fuimos mi apá, mi mamá y yo con el mismo patrón de Sinaloa, tenía campos en Baja California, entonces después nos fuimos para Ensenada. En Ensenada llegamos al rancho Llama y esta Camalú a un lado y de esos ranchos se miraba Vicente Guerrero también. Rancho Llamas fue cuando llegamos por primera vez también [.... incluso a veces lo acompañaba a mi apa a los trabajos, pero yo no trabajaba, pero lo malo era que nos metian en unos tráileres, en cajas de trailer subian a la gente, entonces no había de dónde agarrarse y en cualquier frenón toda la gente se caia" (entrevista con Juan López García, FULT, Villa Benito Juárez, Navolato)

Durante esa temporada en Ensenada, Baja California, Juan López aún no trabaja en los campos agrícolas, sino sólo sus padres se dedican al corte de jitomate y cebollín en el campo La Llama. Su estancia en el estado es de 6 meses. Al terminar la temporada agrícola nuevamente la familia Canelos les hace la invitación para regresar a trabajar a sus campos agrícolas de Sinaloa. Al principio lo dudaron porque se querían quedar en Ensenada, Baja California, sin embargo, como no conocían a nadie y no encontraron a ningún paisano que los apoyara, al final optaron por regresar a Sinaloa.

El retorno de Ensenada, Baja California a Sinaloa es costeado por la familia Canelos. Y así nuevamente Juan López y su familia emprenden el regreso a Sinaloa. Al llegar a Sinaloa, esta vez los llevan al campo San Luís, donde permanecerán durante cinco meses en el corte del jitomate. Las condiciones laborales y de vida son las mismas que las del campo Oaxaca. Al término de la temporada, nuevamente la familia Canelos los invita a ir a trabajar a sus campos agrícolas de Ensenada, Baja California.

El traslado de Sinaloa a Ensenada, Baja California nuevamente es costeado por la familia Canelos. Esta vez fueron llevados a la agroempresa ABC, propiedad también de la familia Canelos, y fueron a trabajar al campo Miramar, donde fueron alojados en sus campamentos. Durante esta temporada agrícola, ya no sólo los padres de Juan López eran los únicos que trabajaban, sino a sus escasos ocho años Juan López por primera vez empezó a trabajar de jornalero agrícola, aunque fue difícil que lo hiciera todos los días, debido a que el trabajo para los niños era muy escaso:

"Si quise trabajar pero había muchísimo niño el que había y pues los más vivos eran los que se apuntaban y pues no alcanzaba en la lista. Eran unos 60 niños yo creo, no se cuantos y los que se arrimaban más, los que daban número eran los que se apuntaban, de hecho habla una cuadrilla de niños que arrancaban hierba y cositas asi nomás. De toda la semana trabajaba un día o dos dias porque no alcanzaba a apuntarme y nos regresábamos varios. Pero trabajar, trabajar no me tocó mucho" (entrevista con Juan López García, FULT, Villa Benito Juárez, Navolato)

Es así, como Juan López empieza a trabajar de jornalero agrícola, aunque lo hiciera por uno o dos días a la semana. El motivo para empezar a trabajar fue para ayudar a sus padres a juntar dinero para irse a vivir a alguna colonia del municipio de Camalú o de Vicente Guerrero porque ya no querían regresar a Sinaloa por sus altas temperaturas de más de $36 \circ \mathrm{C}$ y porque esta vez encontraron mejores condiciones de vida en el campo "Miramar", entre ellas agua potable, galeras de lamina galvanizada y además el clima en Ensenada, Baja California, era más fresco que en Sinaloa.

Casi al finalizar la temporada Juan López y su familia se dedicaron a recorrer varios campos agrícolas en busca de triquis que los ayudaran a encontrar donde vivir en la zona del municipio de Vicente Guerrero. Sin embargo, al finalizar la temporada agrícola no habían encontrado donde alojarse, lo único que encontraron fue trabajo por algunos meses más en el mismo campo que habían trabajado, pero ahora ya no en el corte de jitomate, sino desenterrando estacones de madera. No obstante, que a pesar de que algunas familias triquis que habían compartido las temporadas agrícolas en Sinaloa les insistieron que se fueran con ellos, la familia de Juan López decidió quedarse a vivir en el campo Miramar, de Ensenada, Baja California:

“...íbamos a buscar paisanos de nosotros cuando todavía estaba mi apá, bamos a Rancho el Guaje, íbamos a Lázaro Cárdenas o sea recuerdo por partes [...] ya se había acabado todo el trabajo y ya nada más había arranque de madera y cosas así, entonces las familias de triquis que andaban en Sinaloa e habían dicho a mi apá que se regresara con ellos para acá a Sinaloa, pero él dijo no esta muy feo allá hace mucho calor y aquí no o sea allá en Ensenada es más fresco, el agua está más limpia y el dijo que ahíse iba a quedar" (entrevista con Juan López García, FULT, Villa Benito Juárez, Navolato)

De esta manera, la familia de Juan López decide permanecer en Ensenada, Baja California. Sin embargo, lo que nunca se imaginaron es que su permanencia en el estado iba a cambiar el destino de la familia y sobre todo la vida de Juan 
López. Al mes y medio de estar su padre trabajando en desenterrar estacones de madera ocurre su muerte en un trágico accidente, cuando el carro de redilas que los traía de regreso a los campamentos volcó en la carretera. No obstante, debido a diferentes obstáculos nunca pudieron trasladar el cuerpo de su padre a San Juan Copala, Oaxaca, sino se vieron en la necesidad de sepultarlo en el municipio de Vicente Guerrero, Ensenada, Baja California.

Corre el año de 1986 y Juan López a la edad de nueve años queda huérfano de padre y al no encontrar apoyo para quedarse en Ensenada, Baja California, deciden regresar a San Juan Copala. Después de realizar los trámites de la indemnización reciben sólo $\$ 500.00$ pesos por la muerte de su padre. Al obtener el dinero de la indemnización del accidente de su padre buscan el apoyo de un paisano que los ayuda a regresar a San Juan Copala. Al llegar a San Juan Copala se instalan en un principio con la familia de su madre. Al enterarse de la muerte de su padrastro, Luís (hijo de su madre) llega a Oaxaca y los invita a irse a Sinaloa a vivir al campo (Ángeles) donde vive y trabaja y los fines de semana estudia la preparatoria abierta en Culiacán. La madre de Juan López no acepta y decide hacer su vida en San Juan Copala. Al ser rechazada su propuesta Luís se regresa a Sinaloa.

Con el dinero de la indemnización, la madre de Juan López compra un solar para vivir, porque el terreno de su padre nunca lo pudieron recuperar. Su madre se dedica a hacer tortillas para venderlas en San Juan Copala, así como también cría algunas gallinas para vender los huevos. Juan López a la edad de nueve años trabaja como ayudante de albañil algunos meses en la ampliación de la escuela primaria "Vasco de Quiroga" de San Juan Copala. A los pocos meses de estar viviendo en San Juan Copala y de haber ahorrado dinero, su madre decide que vayan nuevamente a Ensenada, Baja California a recuperar algunas cosas personales. El viaje lo realizan en compañía de otras familias triquis que iban a trabajar a Ensenada, Baja California. Sólo permanecen una semana y regresan nuevamente a San Juan Copala con ayuda de una familia triqui.

A su regreso a San Juan Copala, a la edad de diez años a Juan López su madre lo inscribe en la primaria "Vasco de Quiroga" que se encuentra en San Juan Copala, donde estudiará hasta el tercer año de primaria. La vida de ambos transcurre sin contratiempos durante 3 años, donde su madre sigue vendiendo tortillas y huevos de gallina en San Juan Copala. Por su parte, Juan López sigue estudiando la primaria. La relación con su hermano Luís se hace más estrecha y están en constante comunicación por medio de cartas e incluso les manda dinero. Sin embargo, un día que regresaban familias de jornaleros agrícolas que habían estado trabajado en Sinaloa les comunican que Luís (hijo de su madre) ha muerto.

Al enterarse de la noticia, Juan López y su madre deciden ir a Sinaloa. Esta vez no había quien los acompañara en su viaje y deciden irse solos. Para ese entonces Juan López dominaba el español, porque las clases en la primaria no se enseñaban en triqui, sino en español. Su madre sólo hablaba el triqui, por lo que él se encargo de comprar los boletos para su viaje a Sinaloa. De San Juan Copala viajaron a Juxtlahuaca, de ahí se fueron en autobús a la Ciudad de México, después abordaron otro autobús a Mazatlán y de ahí a Culiacán, llegando a Culiacán se fueron al campo Ángeles a buscar a Luís:

“...nos llega la noticia allá que Luis se había muerto y estaba estudiando bien y dijo mi mamá pues vamonos tu hermano esta muerto, se murió me dijo, bueno, entonces me sacan otra vez de la escuela y yo solo me aventuré pues ya más o menos sabia el español y pues dije me voy a aventurar. Vine a uxtlahuaca pedí boleto a México y si como venía con mi mamá... y en México pedí boleto aquí a Sinaloa pero no había para Sinaloa había para otros lados y me miraban que venía solo pero no -les decía- vengo con mi mamá y me dijeron que si ella no podía hablar, no -les dije- me vendieron boleto a Mazatlán y de Mazatlán tuve que hacer otro traslado a Culiacán y de Culiacán al campo y si llegamos a campo los Ángeles..." (entrevista con Juan López García, FULT, Villa Benito Juárez, Navolato)

Al llegar a Sinaloa al campo Ángeles encuentran a Luís muy enfermo, pero aun vivo. Con ayuda de un doctor (Dr. Santana Palma) lo trasladan al Hospital General de Sinaloa, donde es hospitalizado por unos días. Al ser dado de alta, el hermano del Dr. Santana Palma (Jorge Palma) les ofrece quedarse en su casa hasta que se recupere Luís totalmente. Su madre acepta y deciden quedarse en Sinaloa a cuidar a Luís. Durante su instancia en la casa de Jorge Palma, que se ubicaba en San Pedro, municipio de Navolato, la madre de Juan López insiste en que siga estudiando, por lo que a sus 14 años ingresa nuevamente a la primaria, donde experimenta por primera vez la no discriminación:

“...incluso estuvimos en San Pedro un tiempo con Jorge Palma, hermano del Dr Palma, y me metí a la escuela en San Pedro, es un pueblo, pertenece a Navolato [...] Y existe no tanto la discriminación y ahí en San Pedro eran todo lo contrarios los niños. Se alegraron porque me preguntaron que si yo era de Oaxaca me preguntaban que cómo vivía Benito Juárez, o sea me yo era de Oaxaca me preguntaban que cómo vivía Benito Juárez, o sea, me pedian información pero yo les decía "no se", o sea, lejos de discriminarme me phí estaba en los libros de historia y los niños me pregunto Juarez", o sea que que era de Oaxa libros de historia y los niños me preguntaban y yo les decía Villa Benito Juárez, Navolato) 
Sin embargo, su estancia en la escuela no duró mucho tiempo porque su medio hermano Luís a los pocos días daba signos de que su salud iba mejorando, asimismo, porque su madre no encontraba trabajo deciden irse de San Pedro, Navolato. Al salirse de la casa del hermano del médico que les ofreció hospedaje, se van a trabajar al campo Ángeles, propiedad del agricultor Demerutis, donde Luís ya había vivido algunos años. A sus casi 12 años Juan López empieza a trabajar formalmente como jornalero agrícola al lado de su madre, en el desbrote, amarre y corte de berenjena, chile morrón y tomate. Durante dos años permanecen trabajando en ese campo, donde tenían trabajo todo el año, ya que no sólo se empleaban en la temporada del corte, sino se quedaban a trabajar después de la temporada agrícola a desenterrar estacones que se utilizaban en los cultivos, lo que les permitió vivir durante todo el año en los campamentos.

Cuando salen del campo Ángeles, se van a trabajar al campo Pénjamo, propiedad también del agroempresario Demerutis. En ese campo vivirán entre 4 y 5 años. Los primeros dos años Juan López los trabajo al lado de su madre y su medio hermano Luís. Los siguientes años sólo lo hizo con su madre, porque su medio hermano Luís se fue a Culiacán a estudiar derecho en la Universidad Autónoma de Sinaloa. Durante su estancia en el campo Pénjamo se dedico a cortar berenjena, chille morrón y tomate, pero también fue apuntador, regador y llego a ser mayordomo de una cuadrilla de niños:

“... en San Pedro y si estaba bien pero como no había trabajo ahí para mi mamá pues quiso irse para el campo los Angeles, y me vuelven a sacar otra vez de la escuela, entonces de plano ya no pude estudiar [...] y ahora si ya empece a trabajar bien en el campo, primero estuvimos dos años viviendo y trabajando en el campo Angeles, en el corte de berenjena, chile morron y tomate, después nos fuimos al campo Pénjamo que tambien era de Demerutis, ahí también corté berenjena, chile morrón y tomate, después fui apuntador, mayordomo de una cuadrilla de niños para juntar hierba, pero también trabajaba en el desbrote, el amarre, el corte y llegue a ser regador" (entrevista con Juan López García, FULT, Villa Benito Juárez, Navolato)

El motivo de su salida del campo Penjamo se debió a su medio hermano Luís, que los invitó a vivir a la casa que rentaba en la Sindicatura de Villa Benito Juárez, Navolato. Es así, como Juan López a los 17 años llega por primera vez a Villa Juárez a vivir. Para conseguir trabajo él y su madre recurren a los camioneteros que se encuentran en la sindicatura. El vivir en Villa Juárez les permitió tener mejor conocimiento del mercado de trabajo y acceder a campos agrícolas donde les pagaban mejores salarios.
Durante el primer año que viven en Villa Juárez y estando trabajando en el campo Alamito, Juan López conoce a una triqui de nombre Marcela. A los pocos meses deciden casarse teniendo casi 18 años. Sin embargo, para hacerlo tiene que cumplir con ciertas costumbres triquis, entre ellas, que algún familiar sustituya a su padre para ir a pedir a su futura esposa y también pagar la dote de la novia, aunque no de la misma manera como si estuvieran en San Juan Copala, pero si conservando ciertas características, entre ellas dar una cantidad de dinero y llevar algunos presentes para los padres de la novia.

Juan López recurre a su tío y en compañía de su madre van a pedir la mano de su futura esposa. Como dote de la novia pagan la cantidad de $\$ 7,000.00$ y 5 cajas de refresco y 5 de cervezas, así como varias cajetillas de cigarros. Después de haber aceptado los padres de la novia se casan, donde hacen una fiesta para las familias triquis que se encuentran en Villa Juárez y tratan de que sea como las de San Juan Copala:

"cuando me junté con Marcela la pedimos ahí en campo Alamito [...] stando en Oaxaca es mucho más el gasto y aquí pues fue más poco. Vino mi tío vinieron varias mucho más el gasto y aqui pues fue más poco. Vino $\$ 7,000.00$ más los gastos. Leve 5 cajas de cerveza y 5 de refresco y pues ahíle $\$ 7,000.00$ más los gastos. Lleve 5 cajas de cerveza y 5 de refresco y pues ahí le están ofrece y ofrece pues y pues ya más o menos saben de que se trata y pues pues y pues ya más o menos saben de que se trat a le están ofrece yofrece (entrevista con Juan López García, FULT, Villa Benito Juárez, Navolato)

Después de haberse casado Juan López, sigue trabajando durante 2 o 3 temporadas en varios campos agrícolas, entre ellos campo Pénjamo, campo Campaña y Campo 17, pero ahora lo hace al lado ya no sólo de su madre, sino también con su esposa. El empleo lo consiguen por medio de los camioneteros que se encontraban en Villa Juárez, lo que le facilita que ellos cubran el costo del cuarto donde viven. Un día cuando esta trabajando en un campo agrícola, le llega una invitación por medio de su medio hermano Luís para trabajar de promotor en el Instituto Indigenista Nacional (INI)7. Inmediatamente, acepta el trabajo que consiste en dar pláticas en triqui a jornaleros agrícolas en diferentes campos agrícolas. Las pláticas giran en torno a la higiene en sus galeras, aseo de los niños, lavarse las manos después de ir al baño, la higiene en la preparación de alimentos y prevención de enfermedades.

"Luís me informó, estaba trabajando Luís y otro compañero de San Juan Copala en el programa de SEDESOL y nosotros nos integramos al INI y éramos

7 Hoy Comisión para el Desarrollo de los Pueblos Indígenas. 
varios los que estábamos trabajando pero se recortó el presupuesto y ya [...] bamos y dábamos pláticas a la gente del campo y yo me dirigía con los triquis. Pláticas sobre la higiene que tuvieran ellos en sus casas, que bañaran a sus hijos, cosas así, que se lavaran las manos despues de ir al baño, la higiene de la comida, que lavaran lo que fueran a cocinar, pláticas sobre la prevención de la enfermedad, cosas así. Yo siendo paisano de ellos y llegando y decirles cómo, me van a decir no pues tu tambien caminale. lba y platicaba de otras cosas con ellos y al final reportábamos lo que platicábamos con la gente, no que la higiene y la inventaba porque yo sé cómo es mi gente van a decir "ese está oco" porque ni agua tenemos y nos viene a decir cosas de higiene" (entrevista con Juan López García, FULT, Villa Benito Juárez, Navolato)

Después de permanecer casi un año en el INI, decide abandonar su trabajo de promotor en el INI porque considera que los programas sólo engañan a los jornaleros agrícolas., además, su esposa sufre el aborto de su primer hijo, donde el INI le niega la atención médica. Después de su paso por el INI regresa una temporada más al trabajo agrícola, donde a los 21 años se convierte en papá de un varón y al año siguiente nace su hija. Durante ese tiempo sigue rentando en Villa Juárez y trabajando por medio de los camioneteros.

Cuando seguía trabajando de jornalero agrícola algunos paisanos de é le mencionan que hay trabajo en la procesadora de pollo Bachoco que se encontraba a 30 min. de Villa Juárez. Juan López hace todo lo posible por entrar a trabajar para probar suerte en otro tipo de trabajo, porque considera que de jornalero agrícola nunca va a poder hacer nada para que sus hijos tengan un mejor futuro que él. Sin embargo, no le fue fácil entrar a Bachoco porque varias veces lo rechazaron por su estatura, hasta que después de insistir varias veces es aceptado.

Su estancia laboral en Bachoco es de casi cuatro años, donde en el último año nace su tercer hijo (hija). Al tener acceso al Seguro Social (IMSS) su esposa es atendida en su parto. Asimismo, durante ese tiempo (año 2000) el Sr. Salvador Parra consigue una parcela en Villa Juárez para lotificar solares para jornaleros agrícolas que viven en cuarterías o deciden quedarse a vivir en Villa, Juárez. La amistad de Juan López con el Sr. Salvador Parra hace que este último le regale un solar para que deje de seguir rentando y se instale definitivamente con su familia en Villa Juárez:

"había compañeros que vivían aquí en Villa Juárez y estaban trabajando en Bachoco y fui a pedir trabajo y la secretaria no me quería dar trabajo. Una vez hice la solicitud y me dijo vuelve tal dia y dije a bueno, volví otra vez y no, y ya hasta el final hasta el otro día volví a entrar otra vez y me decía que me miraba muy chico, en la estatura pues, pero que trabajo puede ser más pesado si he trabajado en el campo, qué puede ser más pesado y ya me pusieron a prueba trabaje bien pero me miraban chico de estatura 1.51 creo [...]Si pagaban un poquito más, ahí si teníamos seguro. De ahí salí cuando la Mimi iba naciendo, en insistía que nos viniéramos para ác porque me lo regáó outomáticame él hasta que nos víéramos para acá porque me lo regaló automáticamente, hasta me amenazó, -me dijo- te vas a vivir allá o te quito el solar y entonces si me vine. Porque allá pues... la guevonada de todo mexicano según yo paré los horcones y todo y mi suegro, que falleció ya, nos ayudaron a hacer los hoyos y todo, pusimos lámina arriba ahí la tenía abandonada pues, y me dijo Chava y entonces si me voy le dije, me regalo unas puertas, me regaló unas ventanas, (entrevista con Juan López García, FULT, Villa Benito Juárez, Navolato)

Su trabajo como obrero industrial en la Bachoco era mejor pagado que en los campos agrícolas. Sin embargo, el haber trabajado para el INI y su recorrido por varios campos agrícolas hace que los jornaleros agrícolas lo busquen cada vez más para que los apoye en la resolución de varios problemas que los aquejan. A pesar de que tenía un horario fijo de 8 hrs. en la Bachoco decidió ayudarlos. Pero al ver que eran muchos los problemas decide abandonar su trabajo en la Bachoco y buscar otras alternativas laborales que le permitieran trabajar y al mismo tiempo apoyar a los jornaleros agrícolas, debido a que muchos de los problemas que padecían, él los había vivido hace años.

Al abandonar su trabajo en la Bachoco se traslada a vivir al solar que le ha regalado el señor Salvador Parra y construye una casa con laminas de cartón. Al mismo tiempo su medio hermano Luís decide apoyarlo, y le enseña a reparar zapatos manualmente, oficio que aprendió de un compañero veracruzano de la universidad, que a su vez se lo enseño un amigo que estuvo preso. De esta manera, buscan un local para rentar y trabajar al lado de su medio hermano en su nuevo oficio, esta vez arreglando zapatos.

A partir de entonces decide combinar el trabajo y su activismo en la defensa de los derechos humanos, laborales y civiles de los jornaleros agrícolas que llegan a los campos agrícolas, a las cuarterías y asentados de la sindicatura de Villa Juárez. Sin embargo, al no contar con algún respaldo que lo acredite como miembro de alguna organización y poder representar a los jornaleros agrícolas, decide en el año 2002 crear el Frente Unificación Lucha Triqui (FULT). Al respecto el líder del FULT menciona:

“..nosotros somos triquis de San Juan Copala, salimos de nuestros pueblos porque hay mucha violencia de parte de las autoridades o incluso entre los
mismos triquis, pero también hay mucha pobreza no tenemos para comer, mismos triquis, pero también hay mucha pobreza no tenemos para comer, apenas sembramos tantito maíz, fríjol y calabacitas pero no alcanza, por eso tenemos que venir a Sinaloa a trabajar, pero como esta canijo estar 
regresando todos los años, algunos compañeros decidimos quedarnos a vivir aquí, pero es difícil conseguir un terrenito, pero organizándose se pudo lograr, después tuvimos que luchar para meter luz y agua, por eso yo pensé hace esta organización, pero le pusimos organizacion triqui, porque somos triquis, nacimos allá $y$ a donde vayamos somos triqui, por eso somos del movimiento triqui...ahora cuando vienen los hermanos triquis aqui estamos para ayudarlos cuando tengan cualquier problema o para que pueden descansar en nuestras casas antes de encontrar trabajo en un campo..." (entrevista realizada a Juan de Lucha Triqui, Villa Juárez, Navolato, 2006, citado en Ortiz, 2007:161).

De esta manera nace el FULT, su principal bandera de lucha es la obtención de terrenos para la construcción de vivienda para los triquis que deciden asentarse en la sindicatura de Villa Juárez. Otra lucha fundamental que enarbolan es por el respeto a sus derechos indígenas. También intervienen en los problemas laborales que pueden tener los jornaleros agrícolas. La base social del FULT son jornaleros agrícolas migrantes indígenas asentados en Villa Juárez, pero también jornaleros agrícolas que cada año arriban a Sinaloa. La organización cuenta con el apoyo de aproximadamente 200 personas. Atiende a todos los indígenas triquis que arriban a Sinaloa, pero donde más han desarrollado su trabajo es en la sindicatura de Villa Juárez. No la han querido registrar como una asociación civil, consideran que al hacerlo entran al gobierno y ellos no quieren ser parte de él, lo único que les interesa es ser reconocidos como jornaleros agrícolas indígenas (Ortiz, 2007:161-162).

\section{C) LA EXPERIENCIA DEL CONFLICTO SOCIALEN LA CONSTITUCIÓN} DEL FRENTE UNIFICACIÓN LUCHA TRIQUI

En la historia de vida de Juan López García líder del FULT se puede rastrear la diversidad de conflictos sociales que ha experimentado en su historia migratoria. Como trabajador agrícola tuvo conocimiento de las precarias condiciones de vida y trabajo de miles de trabajadores agrícolas, pero también a temprana edad sufre la muerte de su padre durante su traslado a los campos agrícolas de Baja California. Lo anterior, a la postre los llevó a la creación del Frente Unificación Lucha Triqui y al pasar los años ha convertirse en representante de dicha organización. Retomo dos conceptos para el análisis en la constitución de la organización: el conflicto social y el de actor social.

De acuerdo con Comaroff (1985 citado en Velasco, 2002:158) el conflicto es un factor para la manifestación de la conciencia étnica, que permite que una experiencia sea significativa cuando se modifica el sentido del nosotros o del yo colectivo. Para Guzmán (1989, citado en Velasco, 2002:158) el conflicto es una vía que permite hacer visibles las diferencias étnicas en una dinámica de dominio y resistencia. Asimismo, el conflicto social introduce un estado de desarticulación de orden personal y social, que alimenta no sólo el curso de la acción sino su propio destino.

Sin embargo, el conflicto también posibilita el cambio social. En la historia migratoria del líder del FULT, la experiencia del conflicto social ha jugado un papel importante, porque ha permitido que este actor social ejercite su agencia y cuenten con espacios de maniobra para la realización de sus proyectos. Si bien es cierto lo anterior, se requiere otro tipo de análisis para dar cuenta de la emergencia de este actor social, y me refiero al concepto de "actor social".

Para Long (2007) un actor social es una construcción social que atañe de manera crucial al asunto de agencia, donde la acción social debe de ir más allá de una consideración de habilidad de conocer la conciencia y las interacciones, sino también debe de abarcar los sentimientos, emociones, percepciones, identidades y la continuidad de los agentes (personas) a través del espacio y tiempo. Asimismo, los modelos diferenciales de comportamiento social deben fundarse en "sujetos activos que conocen y sienten" y no ser vistos sólo como consecuencia del efecto diferencial de amplias fuerzas sociales. Por tanto, es importante identificar y caracterizar las diferentes prácticas, estrategias y razonamientos del actor, las condiciones en que surgen, la manera en que se entrelazan, su viabilidad o efectividad para resolver problemas específicos y sus amplias ramificaciones sociales.

Ahora bien, el concepto de "actor social" permite analizar como en la historia de vida y la trayectoria migratoria del líder del FULT, la experiencia del conflicto social ha sido interiorizados y le ha otorgado significado a los eventos o acontecimientos para guiar la acción individual y colectiva que se ha reflejado en la creación de organizaciones étnicas de trabajadores agrícolas y a convertirse en representante de dicha organización.

En la historia de vida del líder del FULT relata su vida en su pueblo antes de migrar, marcado por la pobreza, la discriminación y la violencia. Sin embargo, el conflicto social y la acción colectiva hacen referencia a Baja California y Sinaloa como los lugares que marcaron su vida para emprender una vida de lucha a favor de los trabajadores agrícolas. Ambos estados hacen referencia a las malas condiciones de trabajo y vida, la discriminación, la injusticia de los agricultores y líderes sindicales, aspectos que los llevan a reflexionar que las 
cosas "no andaban bien" y "algo tenía que hacer".

La historia migratoria del líder del FULT, está marcada por las malas condiciones de vida y de trabajo que vive al lado de sus padres en los campos agrícolas de Morelos, Sinaloa y Baja California. Sin embargo, el conflicto social que más ha marcado su vida fue la muerte de su padre en Vicente Guerrero, Baja California. Su padre murió en un accidente carretero cuando el camión de redilas que lo regresaba de trabajar de un campo agrícola se quedo sin frenos y se volteó. Por la falta de apoyo gubernamental, por su corta edad y el monolingüismo de su madre nunca pudo sepultar a su padre en su lugar de origen. A partir de entonces tuvo conocimiento de lo que era involucrarse en un movimiento social para exigir sus derechos laborales:

Cuando mi padre murió estábamos ahí en el ABC de los Canelo y en el Rancho La Loma creo que le dicen, el Miramar, quedaba cerca del mar... nomás, y luego fuimos hasta donde se volteó el carro, ya todo era plano y ya en la bajada donde ba a bajar para el trabajo y el carro choco con un concreto, con una como pila de agua que estaba ahi, y ahi chocó el carro... o sea ahi hacia como una " $\mathrm{T}$ " fromo ahi es una bajada, según el chofer ya habla dicho que le fallaban los frenos al carro, pero le dijeron que así se fuera y entonces es una parte plana Era un torton de redilas, iban como unos 32 o 33 i la vuelta, se fue derecho. murieron muriéson ahi, yo creo que como 28 , murió un triqui tambièn o sea fueron dos nomás ellos. No lo pudimos regresar a mi papá a Oaxaca no habia quien hiciera chiquillo yú nó cono mi mamá no hablaba el español pues yo era el más hizo los hoyos como tipo zanja metieron las cajas como, no sé, como medio hizo los hoyos como tipo zanja metieron las cajas como, no se, como medio metro separados cada uno porque eran muchos... La indemnización la estuvo viendo Benito Garcla y su hermano Moisés García eran del SINGOA8, dijeron que nadie fuera a trabajar, pero hay gente que no quiso, no quiso razonar o simplemente no le interesó, porque de alguna manera pues era dolor ajeno, no era de ellos, entonces llegó el grupo de Benito García y de Fernando y pues sacaron a toda la gente a tomatazos y a pedradas los sacaron, esa fue cuando nos fuimos, nos hicimos la marcha de, de ahí del chorizo hacía San Vicente Guerrero, y a los días pues fue un camión y fuimos hasta Ensenada haciendo plantón, pero según iban a indemnizar con $\$ 1,000.00$ a cada familiar cosa que nos tocó nomás de $\$ 500.00$ y lo demás nunca lo vimos... "ahí fue donde supe lo que era la lucha de participar, de apoyar, de estar en esto"(entrevista a Juan López García, FULT, septiembre, Villa Juárez, Navolato, 2009).

Cuando muere el padre de Juan López García, él apenas contaba con escasos nueve años, sin embargo, a su corta edad la experiencia conflictiva de la migración se hace presente y desde ese momento tiene muy claro que algo tiene que hacer para defender los derechos laborales de los trabajadores, lo que al paso de los años se vio reflejado en la constitución del Frente Unificación Lucha Triqui y su posterior liderazgo en la organización.

Asimismo, la experiencia del conflicto social del líder del FULT muestra una diversidad de espacios de relaciones sociales que se localizan en los lugares de la migración. Mediante el análisis de la experiencias migratoria contenida en el relato de su historia de vida, encontramos diferentes espacios de relaciones sociales, formas de expresión y adversarios del conflicto (cuadro 2 ).

\section{Cuadro 2}

Espacios, formas y adversario del conflicto social en la experiencia migratoria

\begin{tabular}{|c|c|c|c|}
\hline Líder indígena & $\begin{array}{l}\text { Espacio del } \\
\text { conflicto }\end{array}$ & $\begin{array}{l}\text { Forma de } \\
\text { expresión }\end{array}$ & Adversario \\
\hline $\begin{array}{c}\text { Juan López García } \\
\text { FULT }\end{array}$ & Laboral & $\begin{array}{l}\text { - Malas } \\
\text { condiciones de } \\
\text { vida y de trabajo } \\
\text { en los campos } \\
\text { agrícolas de } \\
\text { Morelos, Sinaloa } \\
\text { y Baja California } \\
\text { - Muerte de su } \\
\text { padre en Baja } \\
\text { California }\end{array}$ & $\begin{array}{l}\text { - Contratistas } \\
\text { - empresarios } \\
\text { agrícolas } \\
\text { - líderes sindicales } \\
\text { - Instituciones } \\
\text { gubernamentales }\end{array}$ \\
\hline
\end{tabular}

Fuente: Elaboración propia con datos de campo.

Podemos distinguir en la experiencia migratoria del líder del FULT como espacios del conflicto social, las relaciones laborales. En cada uno de estos espacios de relaciones sociales el conflicto social tiene diferentes formas de expresión y un conjunto de adversarios específicos. Las diferentes formas de expresión se dan desde la discriminación por su pertenencia étnica hasta las 
malas condiciones de trabajo y vida en el lugar de la migración. Lo sobresaliente es que esta discriminación es interiorizada por los actores sociales y sirve para crear la resistencia.

La experiencia del conflicto social fue fundamental para la resistencia que se vio reflejada en la construcción social de las fronteras de la condición étnica y su clase social. La distinción de los espacios de relaciones sociales donde se expresa el conflicto social contribuye a delimitar a los otros como adversarios (empresarios agrícolas, funcionarios de gobierno, líderes sindicales, etc.) a la vez que el nosotros como aliados (trabajadores agrícolas) que posteriormente se ve reflejado en la creación del Frente Unificación Lucha Triqui.

\section{CONCLUSIONES}

La trayectoria de vida y migración que ha experimentado el líder del FULT ha estado marcada por eventos de discriminación étnica, pobreza y violación a sus derechos laborales y humanos. De esta manera, es como la reivindicación de las condiciones de trabajo y la identidad étnica adquiere diversos planos, que obedecen tanto a su origen étnico-campesino como a su condición de migrante-asalariado. Lo anterior, se debe a que su identidad de origen fue ampliada hasta convertirse en un actor social que agrupo demandas y concepciones anteriormente separadas, con un discurso que uso significantes ya conocidos pero atribuyéndoles nuevos significados. Esta particular no es una manifestación aislada, es parte de expresiones más amplias, parte de un movimiento que busca mejores condiciones laborales y de vida en los campos agrícolas, igualdad social y un mayor respeto a la diversidad cultural. De esta manera, elementos de clase social e identidades étnicas dan sentido al surgimiento de organizaciones de carácter étnico de trabajadores agrícolas. Se puede inferir que el lugar de origen de los líderes revela la diversidad de formas de organizarse por la pertenencia a una comunidad

Podemos distinguir al líder del FULT como actor social por las condiciones en que surge, la identidad obrero agrícola-indígena, sus intereses, creencias y percepciones y el entorno de oportunidades en el que despliega su actuación. Un factor clave para la constitución como actores sociales fue que su identidad de origen a través de la migración fue ampliada y le dio sentido al reforzamiento de su identidad en los lugares de asentamiento para reclamar mejores condiciones de trabajo y de vida de los trabajadores agrícolas pero con un énfasis étnico.

\section{BIBLIOGRAFÍA}

Arizpe, Lourdes (1980) Migración, etnicismo y cambio económico, Centro de Estudios Sociológicos, El Colegio de México, México.

Besserer, Federico (1998) "Mixtepec: una comunidad multicéntrica y multinacional" Ponencia presentada en el IV Coloquio Paul Kirchhoff, IIAUNAM, 19 al 30 de octubre.

Betanzos Ocampo, Percy (2007) Fumigados. Una revisión general sobre el uso, manejo, control y problemática de plaguicidas en los altos de Morelos, Tesis de licenciatura en Antropología Social, UAEM, Morelos.

Bourdieu, Pierre (1991) El sentido práctico, Taurus, Buenos Aires.

Bustamante, Jorge (1986) “Migración indígena a Baja California Norte”, En: México Indígena, INI, México, pp. 21-22

Fox, Jonathan y Gaspar Rivera Salgado (2004) Indígenas mexicanos migrantes en los Estados Unidos, Cámara de Diputados-Universidad Autónoma de Zacatecas-Miguel Ángel Porrua, México.

CAADES (2010) Resumen ejecutivo. Cierre de ciclo de hortalizas, temporada 2009-2010, Sinaloa. www.cidh.org.mx

Centro de Derechos Humanos de la Montaña “Tlachinollan" (2011) Migrantes somos y en el camino andamos, Centro de Derechos Humanos de la Montaña "Tlachinollan" A.C, Tlapa, Guerrero.

Gaméz Gastélum, Rosalinda (2006) Hacia una cultura organizacional híbrida en empresas hortícolas, UAS, Culiacán, Sinaloa.

Guerra Ochoa, María Teresa (1996) "La fuerza de trabajo en la horticultura sinaloense" en Hubert C de Grammont y Héctor Tejera Gaona (coords.). Los nuevos actores y procesos políticos en el campo. Vol 4. UAM-Azcapotzalco, UNAM, INAH, Plaza y Valdes, pp. 131-151

Granados, Armando, (2002), "El impacto del cambio del patrón de cultivos en la inmigración en Sinaloa”, En: Travesaño, núm. 10, Guanajuato, México, pp. 22-25.

Guzmán, Elsa (1991) Persistencia y Cambio: Los campesinos jitomateros de Morelos, Tesis de Maestría en Desarrollo Rural. UAM-X, México, 1991.

INEGI (2000) XI/ Censo General de Población y Vivienda, Instituto Nacional de Estadística, Geografía e Informática, México.

Iwanska, Alicia (1973) “¿Emigrantes o commuterss? (indios mazahuas en la ciudad de México)" En: América Indígena, Vol. XXXIII, No. 2, abril-junio, México. Kemper, Robert (1976) Campesinos en la ciudad. Gente de Tzintzuntzan, 
SEP-Setentas, México

Lara Flores Sara y Hubert C. de Grammont (2011) "Reestructuraciones productivas y encadenamientos migratorios en las hortalizas sinaloenses" en: Sara María Lara Flores (Coorda), Los "encadenamientos migratorios" en espacios de agricultura intensiva, El Colegio Mexiquense- Miguel Ángel Porrúa, México, pp.33-78

Leal, Alejandra (2006) "La identidad mixteca en la migración al norte:el caso del Frente Indígena Oaxaqueño Binacional", Amérique Latine Histoire et Mémoire, Numéro 2-2001 - Migrations: Guatemala, Mexique , [En ligne], mis en ligne le 13 janvier 2006. URL : http://alhim.revues.org/document610.html. Consulté le 26 juillet 2008.

Lewis, Oscar (1986) “Urbanización sin desorganización: estudio de caso” En: Ensayos Antropológicos, Grijalbo, México, pp. 545-561

Long Norman (2002) «An Actor-oriented Approach to Development Intervention," in APO Seminar on Rural Life Improvement for Community Development. Japan: Asian Productivity Organization.

Long Norman (2007) Sociología del desarrollo: una perspectiva centrada en el actor, El Colegio de San Luis- CIESAS, México.

Méndez y Mercado, Leticia (1985) Migración: decisión involuntaria, Instituto Nacional Indigenista, Serie de Antropología Social, No. 72, México.

Odena Güemes, Lina (1983) “Enclaves étnicos en la ciudad de México y área metropolitana" En: Anales, México, pp.127-163

Ortiz Marín, Celso (2007) Las organizaciones de jornaleros agrícolas indígenas en Sinaloa, Departamento de Sociología Rural-Universidad Autónoma Chapingo, México.

Ortiz Marín, Celso (2010) “Migración indígena, proceso de asentamiento y organizaciones de migrantes en la horticultura sinaloense: El caso de la sindicatura de Villa Benito Juárez, Navolato, Sinaloa" en Artículos y Ensayos de Sociología Rural, Numero 9. Departamento de Sociología Rural- Universidad Autónoma de Chapingo, México. pp. 23-38

París Pombo, María Dolores (2006) La historia de Martha: vida de una mujer indigena por los largos caminos de la Mixteca a California, UAM-Xochimilco, México.

PEE/SHPyT (2001), Anexo del segundo informe de gobierno Juan S. Millán, Sinaloa, noviembre.

Posada, Florencio y Benito García (1986) "El movimiento de los obreros agrícolas en Sinaloa, 1977-1983, en: C. de Grammont, Hubert. Asalariados agrícolas y sindicalismo en el campo mexicano. Juan Pablos Editor, IIS-UNAM, México.

Programa de salud y apoyo al migrante-SSA (2001) El diagnóstico en Sinaloa. Jornaleros agrícolas migrantes. Presentación de estados, Culiacán, Sinaloa.

Secretaria de Salud (2001) Diagnóstico de Sinaloa 2001. Presentación de estados, jornaleros agrícolas migrantes, Sinaloa.

SEDESOL,(1999)ProgramaconJornalerosAgrícolas, CoordinaciónEstatalGuerrero, Informe de migración ciclo otoño- invierno 1998/99, México, 1999.

Sinagawa, Montoya, Herberto (1987) Sinaloa, agricultura y desarrollo, CAADES, Culiacán, Sinaloa.

Taylor B., Ronald (1979) Chávez: la interminable batalla por la dignidad, EDAMEX, México.

Velasco Ortiz, Laura (2002) El regreso de la comunidad: migración indígena y agentes étnicos. Los mixtecos en la frontera México-Estados Unidos, El Colegio de México, El Colegio de la Frontera Norte, México.

\section{Celso Ortiz Marín}

ortizcelso@hotmail.com

ic. en Antropología Social (ENAH), Maestro en Ciencias en Sociología Rural (UACH), Doctor en Estudios Sociales línea Estudios Laborales (UAM-I). Estancia Posdoctoral en el Posgrado de Ciencias en Ciencias Agrarias, Departamento de Sociología Rural (UACH). Profesor-Investigador de Tiempo Completo en la Universidad Autónoma Indígena de México. Miembro del Sistema Sinaloense de Investigadores y Tecnólogos. Reconocimiento de Profesor de Tiempo Completo con Perfil Deseable PROMEP-SEP. 